\title{
YURI CERQUEIRA DOS ANJOS, Marcel Proust et la presse de la Belle Époque
}

\section{Ludovico Monaci}

\section{(2) OpenEdition}

\section{Journals}

\section{Edizione digitale}

URL: http://journals.openedition.org/studifrancesi/16657

DOI: 10.4000/studifrancesi. 16657

ISSN: 2427-5856

\section{Editore}

Rosenberg \& Sellier

\section{Edizione cartacea}

Data di pubblicazione: 1 juillet 2019

Paginazione: 187

ISSN: 0039-2944

\section{Notizia bibliografica digitale}

Ludovico Monaci, «Yuri cerqueira dos anjos, Marcel Proust et la presse de la Belle Époque», Studi Francesi

[Online], 187 (LXIII | I) | 2019, online dal 01 juillet 2019, consultato il 25 janvier 2021. URL: http:// journals.openedition.org/studifrancesi/16657 ; DOI: https://doi.org/10.4000/studifrancesi. 16657

Questo documento è stato generato automaticamente il 25 janvier 2021.

\section{@(๑) $\Theta \Theta$}

Studi Francesi è distribuita con Licenza Creative Commons Attribuzione - Non commerciale - Non opere derivate 4.0 Internazionale. 


\title{
YURI CERQUEIRA DOS ANJOS, Marcel Proust et la presse de la Belle Époque
}

\author{
Ludovico Monaci
}

\section{NOTIZIA}

YURI CERQUEIRA DOS ANJOS, Marcel Proust et la presse de la Belle Époque, Paris, Champion, 2018, «Recherches proustiennes» 42, 344 pp.

1 Grazie a questo studio, la variegata ed eterogenea produzione giornalistica di Marcel Proust si ritaglia una propria autonomia all'interno del corpus autoriale, affrancandosi dall'idea dominante che la vorrebbe aprioristicamente relegata in una posizione ancillare rispetto alla Recherche.

2 Nella «Première Partie: Fondements» (pp. 17-68) viene inquadrata la situazione storicoculturale della Belle Époque: Yuri Cerqueira dos Anjos sottolinea come, a fronte del continuo processo di democratizzazione della stampa, i rapporti tra la letteratura e il giornalismo siano sempre più ambigui e controversi. Dopo aver tracciato un quadro della tendenza generale, si passa al caso particolare: sebbene non possa essere annoverato tra gli «écrivains-journalistes», Proust è regolarmente impegnato nella scrittura di articoli destinati alla stampa, come testimoniato dalla sezione «Bibliographie» (pp. 319-334), che riporta i titoli di tutti i suoi écrits de presse, pubblicati tra il 1890 e il 1922.

3 La «Deuxième Partie: Autour de l'ethos» (pp. 69-154) presenta la stampa come un sistema semiotico veicolato dall'immagine di chi scrive. Un'attenzione particolare è rivolta al nome (o allo pseudonimo) col quale Marcel Proust si firma negli articoli a stampa: primo luogo di costruzione dell'ethos, esso varia in relazione al supporto (giornale, rivista, periodico), al contesto mediatico in cui l'autore si inscrive («Le Mensuel», «Le Banquet», «La Revue Blanche», «Le Gaulois», «Le Figaro») e al tipo di pubblicazione (articoli mondani, articoli di contenuto artistico-letterario, necrologi). Il 
trattamento dei contenuti cronachistici in funzione delle esigenze autoriali è il secondo grande polo che veicola la costruzione dell'ethos.

Nella «Troisième Partie: Poétique de la presse» (pp. 155-244), l'autore approfondisce la questione stilistica, avvalendosi di un ricco apparato testuale: gli écrits de presse all'interno dei manoscritti NAF 16612, NAF 16632, NAF 16634 e NAF 16636, alcuni passi della corrispondenza, del Contre Sainte-Beuve, di «Mondanité de Bouvard et Pécuchet»e di Pastiches et mélanges. Dalla trattazione emerge come le riflessioni che Proust conduce sullo stile letterario e sull'arte della scrittura tengano conto, per analogia o per opposizione, dello stile giornalistico.

5 La "Quatrième Partie: L'imaginaire médiatique» (pp. 245-302) conchiude il discorso trattando della dimensione meta-discorsiva della stampa durante la Belle Époque, ovvero delle riflessioni che gli addetti ai lavori avanzano sulla loro stessa entreprise. Analogamente, Proust, impegnato nel mondo editoriale sin dai tempi del liceo (con la redazione del «Lundi» e della «Revue Lilas»), propone nei suoi articoli discorsi "metamediatici" soffermandosi, non senza ironia, sui tipi di lettore, sul giornalista-tipo e sullo spazio simbolico della comunicazione. Sulla scia di altri studi, l'autore rimarca come tali ragionamenti sull'immaginario della presse si riverberino nella Recherche.

Nel complesso, Yuri Cerqueira dos Anjos ha il grande merito di aver analizzato sistematicamente la produzione giornalistica di Marcel Proust mettendone in risalto l'originalità: l'analisi contestuale della temperie culturale della Belle Époque e il confronto dialettico tra l'esperienza personale dello scrittore e quella più generale della collettività mediatica costituiscono senza dubbio il valore aggiunto della ricerca. 